\title{
Application of Response Surface Methodology for Modeling and Optimization of Surface Roughness and Electric Current Consumption in Turning Operation
}

\author{
Charles S.C Punuhsingon*, Soo-Cheol $\mathrm{Oh}^{\#}$ \\ $(*$,\# Pukyong National University)
선삭 작업에서 표면조도와 전류소모의 모델링 및 최적화를 위한 반응표면방법론의 응용

Charles S.C Punuhsingon", 오수철\#

(Received 2 June 2014, received in revised form 30 July 2014; accepted 19 August 2014)

\begin{abstract}
This paper presents an experiment on the modeling, analysis, prediction and optimization of machining parameters used during the turning process of the low-carbon steel known as ST40. The parameters used to develop the model are the cutting speed, the feed rate, and the depth of the cut. The experiments were carried out under various conditions, with three level of parameters and two different treatments for each level (with and without a lubricant), to determine the effects of the parameters on the surface roughness and electric current consumption. These effects were investigated using response surface methodology (RSM). A second-order model is used to predict the values of the surface roughness and the electric current consumption from the results of experiments which collected preliminary data. The results of the experiment and the predictions of the surface roughness and electric current consumption under both treatments were found to be nearly identical. This result shows that the feed rate is the main factor that influences the surface roughness and electric current consumption.
\end{abstract}

Key Words : Turning Operation(선삭작업), Response Surface Methodology(반응표면방법론), Surface Roughness(표면조도), Electric Current Consumption(전류소비)

\section{Introduction}

\# C. A. : Department of Systems Management \& Engineering, Pukyong National University

E-mail : scoh@pknu.ac.kr

* Department of Systems Management \& Engineering, Graduate School, Pukyong National University, Busan, Korea
Turning is one of machining processes which are very important and widely used in the industry. Parameters on turning process are cutting speed, feed rate and depth of cut. Surface roughness is a widely used index of product quality and in most cases a technical requirement for mechanical products $^{[2]}$. Very few research attempts have been 
done to estimate the significance of energy required for the machining process. Recent increase in energy demand and constraints in supply of energy becomes a priority for the manufacturing industry ${ }^{[1]}$.

RSM is a collection of statistical and mathematical methods that are useful for modeling and analyzing engineering problems. In this technique, the main objective is to optimize the response surface that is influenced by various process parameters. RSM also quantifies the relationship between the controllable input parameters and the obtained response surfaces ${ }^{[1]}$. Bhattacharya at al. ${ }^{[3]}$ have evaluated the contribution of cutting parameters (cutting speed, feed rate and depth of cut) during high speed machining on the workpiece surface finish and corresponding machine power consumption using Taguchi's orthogonal array design and analysis of variance(ANOVA).

According to Makadia and Nanavati ${ }^{[10]}$, the feed rate is the main factor followed by tool nose radius which influences the surface roughness. The surface roughness was found to be increased with the increase in the feed rate and it is decreased with increase in the tool nose radius. An empirical model has been created by Ezilarasan at al. ${ }^{[5]}$ for predicting the cutting force, flank wear and surface roughness through response surface methodology. The feed rate was found to influence the cutting force and surface roughness more significantly than the cutting speed and depth of cut. Kaynak ${ }^{[9]}$ presents the experimental results of cryogenic machining of inconel 718, a high-temperature aerospace alloy, and comparison of its performance in dry and minimum quantity lubrication machining.

To control the surface roughness and electric current consumption under various conditions of machining parameters and treatments for each level (with and without lubricant), it is necessary that the machining parameters should be optimized. The problem definition in this paper is to model, analyze, predict and optimize the values of surface roughness and electric current consumption (dual response) with two different treatments for each level (with and without lubricant). Therefore, the objective of this paper is to model, analyze, predict and optimize the value of the response using RSM.

\section{Experimental details}

\subsection{Workpiece material, machine, and equipment}

The low carbon steel of ST 40 material of 32 $\mathrm{mm}$ diameter and $150 \mathrm{~mm}$ length(Fig. 1) was used for all the experiments.

The experimental study was carried out on a KNUTH Type DM 1000A lathe(Fig. 2), which has the following specifications: serial no 54715, year of construction 2012, total power $5.8 \mathrm{kw}$, voltage 400 volt, frequency $50 \mathrm{~Hz}$, spindle speed range 30-1600 $\mathrm{rpm}$, feed range $0.055-1.00 \mathrm{~mm} / \mathrm{rev}$.

The surface roughness was measured using the Surfcoder SE 500 with the following specifications standard: JIS2001/ISO97, cut off: $0.8 \mathrm{~mm}$, filter: Gauss, sampling length: $0.8 \mathrm{~mm}$, evaluation length: $4.00 \mathrm{~mm}$, measuring speed: $0.5 \mathrm{~mm} / \mathrm{s}$. Three measurements were used to characterize the surface roughness at each cutting condition. Electrical current consumption is measured during the machining process, using digital ampere meter (AC clamp-On Ammeter) Krisbow KW06-287.

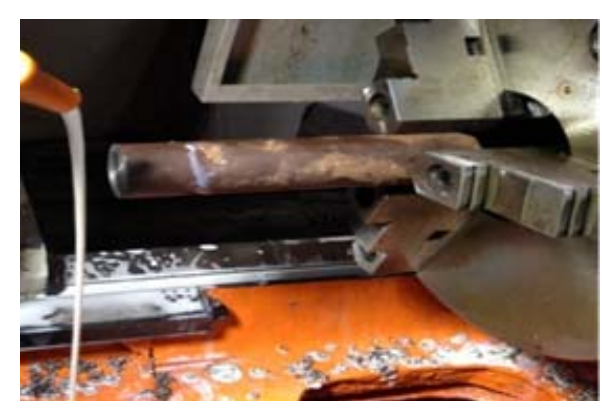

Fig. 1 Workpiece material 


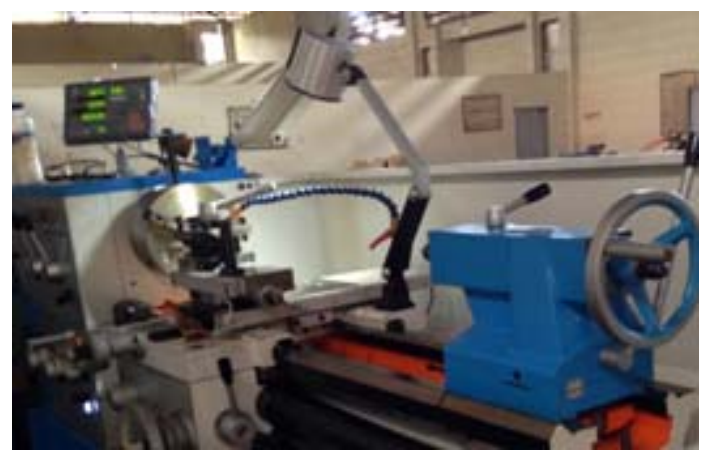

Fig. 2 Lathe Merk KNUTH type DM 1000A
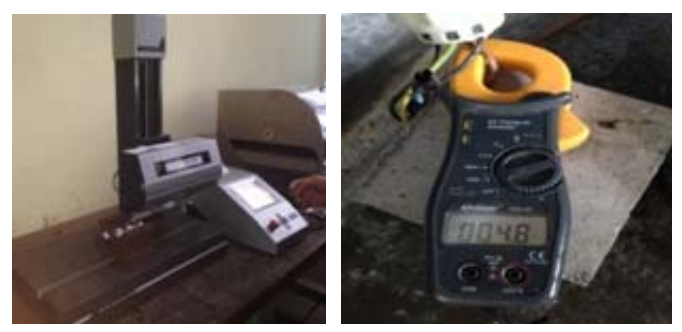

Fig. 3 Measurement equipment (a) surface roughness, (b) AC clamp-On Ammeter

\subsection{Plan of experiments}

In this experiment we use three factors, namely, cutting speed, feed rate and depth of cut, in which each has three values corresponding to three levels (low, middle and high). Two responses - surface roughness $(\mu \mathrm{m})$ and electric current consumption (Ampere) with two different treatments with lubricant and without lubricant - are given. RSM was used to select the level of factor (cutting speed, feed rate and depth of cut) with central composite as type of design to conduct the turning experiments. MINITAB 14 software was used for modeling and analysis. Summary and information of the factors and their levels can be seen in Table 1 . The surface roughness and electric current consumption were measured at three times and the average was taken as the responses. The experimental results are given in Table 2.
Table 1 Input parameters and their levels

\begin{tabular}{c|c|c|c}
\hline \hline \multirow{2}{*}{ Factors } & \multicolumn{3}{|c}{ Level } \\
\cline { 2 - 4 } & Low & Middle & High \\
\hline $\begin{array}{c}\text { Cutting Speed (V) } \\
(\mathrm{m} / \mathrm{min})\end{array}$ & 13 & 41.5 & 70 \\
\hline $\begin{array}{c}\text { Feed Rate (f) } \\
\text { (mm/rev) }\end{array}$ & 0.055 & 0.1125 & 0.17 \\
\hline $\begin{array}{c}\text { Depth of Cut (d) } \\
(\mathrm{mm})\end{array}$ & 0.3 & 0.6 & 0.9 \\
\hline
\end{tabular}

\section{Modeling of the machining parameters using the response surface methodology}

RSM is a collection of mathematical and statistical techniques that are useful for modeling and analysis in applications where a response is influenced by generally more than one factor. The purpose of RSM is to establish the mathematical relationship between an output parameter (responses) and a set of input parameters (factors). The second-order model has the general form as follows.

$$
Y=\beta_{0}+\sum_{i=1}^{k} \beta_{i} X_{i}+\sum_{i=1}^{k} \beta_{i j} X_{i}^{2}+\sum \sum \beta_{i j} X_{i} X_{j}+\epsilon
$$

where the expected response is $Y$ and $\beta^{\text {s }}$ s are the regression coefficients to be estimated and $\epsilon$ the residual measure, results from an experimental error in the observations. The second order response surface representing the surface roughness with lubricant (WL_SR) can be expressed as a function of the cutting parameters, such as the cutting speed(V), feed rate(f) and depth of cut(d). The relationship between the response and the machining parameters is given in the following equation.

$\begin{aligned} W L_{-} S R= & \beta_{0}+\beta_{1}(V)+\beta_{2}(f)+\beta_{3}(d)+\beta_{4}\left(V^{2}\right)+\beta_{5} \\ & \left(f^{2}\right)+\beta_{6}\left(d^{2}\right)+\beta_{7}(V d)+\beta_{8}(V f)+\beta_{9}(f d)\end{aligned}$ 
Table 2 Experimental conditions and results

\begin{tabular}{|c|c|c|c|c|c|c|c|c|c|}
\hline \multirow{4}{*}{$\begin{array}{l}\text { Run } \\
\text { Order }\end{array}$} & \multirow{4}{*}{$\begin{array}{c}\text { Pt } \\
\text { Type }\end{array}$} & \multirow{4}{*}{ Blocks } & & & & \multicolumn{4}{|c|}{ Response } \\
\hline & & & \multirow{2}{*}{\multicolumn{3}{|c|}{ Factor }} & \multicolumn{2}{|c|}{ With Lubricant } & \multicolumn{2}{|c|}{ Without Lubricant } \\
\hline & & & & & & \multirow{2}{*}{$\begin{array}{c}\begin{array}{c}\text { Surface } \\
\text { Roughness (SR) }\end{array} \\
\text { WL_SR (average) }\end{array}$} & \multirow{2}{*}{$\begin{array}{c}\begin{array}{c}\text { Electric Current } \\
\text { Consumption } \\
\text { (CC) }\end{array} \\
\text { WL_CC (average) }\end{array}$} & \multirow{2}{*}{$\begin{array}{c}\begin{array}{c}\text { Surface } \\
\text { Roughness (SR) }\end{array} \\
\text { NL_SR (average) }\end{array}$} & \multirow{2}{*}{$\begin{array}{c}\begin{array}{c}\text { Electric Current } \\
\text { Consumption } \\
\text { (CC) }\end{array} \\
\mathrm{NL} \text { CC (average) }\end{array}$} \\
\hline & & & $\begin{array}{l}\text { Cutting } \\
\text { speed } \\
\text { (m/min) }\end{array}$ & $\begin{array}{l}\text { Feed rate } \\
(\mathrm{mm} / \mathrm{Rev})\end{array}$ & $\begin{array}{c}\text { Dept of } \\
\text { cut }(\mathrm{mm})\end{array}$ & & & & \\
\hline 1 & 1 & 1 & 13 & 0.17 & 0.9 & 7.671 & 4.400 & 4.474 & 4.733 \\
\hline 2 & -1 & 1 & 13 & 0.1125 & 0.6 & 5.252 & 4.400 & 5.135 & 4.733 \\
\hline 3 & 1 & 1 & 70 & 0.055 & 0.9 & 1.491 & 4.567 & 2.888 & 4.900 \\
\hline 4 & 1 & 1 & 13 & 0.055 & 0.3 & 1.660 & 4.400 & 2.244 & 4.667 \\
\hline 5 & -1 & 1 & 41.5 & 0.1125 & 0.3 & 3.060 & 4.767 & 3.060 & 4.833 \\
\hline 6 & 0 & 1 & 41.5 & 0.1125 & 0.6 & 3.274 & 4.833 & 3.845 & 5.000 \\
\hline 7 & 1 & 1 & 70 & 0.17 & 0.9 & 7.440 & 4.700 & 5.572 & 5.167 \\
\hline 8 & -1 & 1 & 70 & 0.1125 & 0.6 & 2.067 & 4.533 & 2.100 & 4.800 \\
\hline 9 & 0 & 1 & 41.5 & 0.1125 & 0.6 & 3.168 & 4.800 & 4.465 & 4.967 \\
\hline 10 & 1 & 1 & 70 & 0.17 & 0.3 & 2.926 & 4.667 & 2.768 & 4.733 \\
\hline 11 & 0 & 1 & 41.5 & 0.1125 & 0.6 & 2.107 & 4.933 & 5.256 & 5.033 \\
\hline 12 & -1 & 1 & 41.5 & 0.17 & 0.6 & 1.963 & 4.900 & 4.434 & 5.033 \\
\hline 13 & 0 & 1 & 41.5 & 0.1125 & 0.6 & 2.772 & 4.867 & 4.079 & 5.033 \\
\hline 14 & 1 & 1 & 70 & 0.055 & 0.3 & 2.990 & 4.667 & 1.746 & 4.800 \\
\hline 15 & -1 & 1 & 41.5 & 0.055 & 0.6 & 2.517 & 4.933 & 2.503 & 5.067 \\
\hline 16 & 0 & 1 & 41.5 & 0.1125 & 0.6 & 3.232 & 4.967 & 3.271 & 5.067 \\
\hline 17 & -1 & 1 & 41.5 & 0.1125 & 0.9 & 3.232 & 5.067 & 2.438 & 5.033 \\
\hline 18 & 1 & 1 & 13 & 0.17 & 0.3 & 7.842 & 4.767 & 6.237 & 4.667 \\
\hline 19 & 0 & 1 & 41.5 & 0.1125 & 0.6 & 3.447 & 5.200 & 3.211 & 5.067 \\
\hline 20 & 1 & 1 & 13 & 0.055 & 0.9 & 3.379 & 4.767 & 2.306 & 4.667 \\
\hline
\end{tabular}

The experimental results were used to develop the mathematical models using RSM to determine the relationship between the surface roughness and machining parameters with lubricant. Substituting the values in Eq. (2), the following equation is obtained.

$$
\begin{aligned}
W L_{-} S R= & 5.03417-0.123329 \mathrm{~V}+41.6729 f- \\
& 11.3074 d+0.00142947 V^{2}-78.1578 f^{2} \\
& +7.19545 d^{2}-0.350038 \mathrm{Vf}+ \\
& 0.0214474 \mathrm{Vd}+29.8768 f d
\end{aligned}
$$

ANOVA was applied to study the effect of input parameters on the surface roughness with lubricant. Table 3 shows that the feed rate is significant factor on the surface roughness ( $\mathrm{p}$ value $=0.047$ or less than 0.05 ) followed by cutting speed and depth of cut.

The experimental results were used to develop the mathematical models using RSM to determine the relationship between the electric current
Table 3 Results of analysis of variance for surface roughness with lubricant

\begin{tabular}{l|r|r|r|r|r|l}
\hline \hline \multicolumn{1}{c|}{ Source } & DF & Seq SS & Adj SS & Adj MS & \multicolumn{1}{c|}{ F } & \multicolumn{1}{l}{ P } \\
\hline Cutting speed & 1 & 7.903 & 4.655 & 4.655 & 2.41 & 0.146 \\
\hline Feed rate & 1 & 24.980 & 9.435 & 9.435 & 4.89 & 0.047 \\
\hline Depth of cut & 1 & 2.242 & 2.180 & 2.180 & 1.13 & 0.309 \\
\hline Cutting speed*Feed rate & 1 & 2.632 & 10.399 & 10.399 & 5.39 & 0.039 \\
\hline Cutting speed*Depth of cut & 1 & 0.269 & 5.071 & 5.071 & 2.63 & 0.131 \\
\hline Feed rate*Depth of cut & 1 & 2.125 & 2.185 & 2.185 & 1.13 & 0.308 \\
\hline $\begin{array}{l}\text { Cutting speed*Feed rate* } \\
\text { Depth of cut }\end{array}$ & 1 & 7.807 & 7.807 & 7.807 & 4.05 & 0.067 \\
\hline Error & 12 & 23.154 & 23.154 & 1.929 & & \\
\hline Total & 19 & 71.112 & & & & \\
\hline \hline
\end{tabular}

consumption with lubricant(WL_CC) and machining parameters. Substituting the values in Eq. (2), the following equation is obtained.

$$
\begin{aligned}
W L_{-} C C= & 4.05921+0.0418690 \mathrm{~V}-0.926211 f \\
& -0.104792 d-4.93578 E-04 \times V^{2}+ \\
& 14.8479 f^{2}+0.601010 d^{2}+0.00991609 \mathrm{Vf} \\
& -0.00102339 \mathrm{Vd}-4.42029 f d
\end{aligned}
$$


Table 4 Results of analysis of variance for electric current consumption with lubricant

\begin{tabular}{l|c|c|c|c|c|c}
\hline \multicolumn{1}{c|}{ Source } & DF & Seq SS & Adj SS & Adj MS & F & P \\
\hline Cutting spped & 1 & 0.01600 & 0.06805 & 0.06805 & 1.07 & 0.321 \\
\hline Feed rate & 1 & 0.00100 & 0.10779 & 0.10779 & 1.70 & 0.217 \\
\hline Depth of cut & 1 & 0.00529 & 0.13173 & 0.13173 & 2.08 & 0.175 \\
\hline Cutting speed*Feed rate & 1 & 0.00211 & 0.06480 & 0.06480 & 1.02 & 0.332 \\
\hline Cutting speed*Depth of cut & 1 & 0.00061 & 0.08131 & 0.08131 & 1.28 & 0.280 \\
\hline Feed rate*Depth of cut & 1 & 0.04651 & 0.14111 & 0.14111 & 2.22 & 0.162 \\
\hline $\begin{array}{l}\text { Cutting speed*Feed rate* } \\
\text { Depth of cut }\end{array}$ & 1 & 0.09461 & 0.09461 & 0.09461 & 1.49 & 0.246 \\
\hline Error & 12 & 0.76144 & 0.76144 & 0.06345 & & \\
\hline Total & 19 & 0.92757 & & & & \\
\hline
\end{tabular}

ANOVA was applied to study the effect of the input parameters on the electric current consumption. Table 4 shows that there are no significant factors because all the $\mathrm{p}$ value is greater than 0.05 . However, factors that affect the electric current consumption are depth of cut followed by feed rate and cutting speed.

The experimental results were used to develop the mathematical models using RSM to determine the relationship between the surface roughness without lubricant(NL_SR) and machining parameters. Substituting the values in Eq. (2), the following equation is obtained.

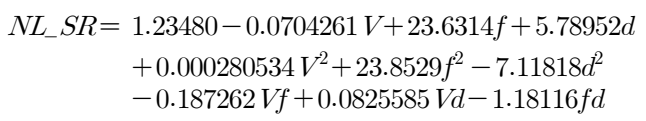

ANOVA was applied to study the effect of the input parameters on the surface roughness. Table 5 shows that only feed rate has significant factor on the surface roughness without lubricant ( $\mathrm{p}$ value $=$ 0.028 or less than 0.05 ) followed by depth of cut and cutting speed.
Table 5 Results of analysis of variance for surface roughness without lubricant

\begin{tabular}{l|c|c|c|c|c|c}
\hline \multicolumn{1}{c|}{ Source } & DF & Seq SS & Adj SS & Adj MS & \multicolumn{1}{l|}{ F } & \multicolumn{1}{l}{ P } \\
\hline Cutting spped & 1 & 2.8324 & 0.0438 & 0.0438 & 0.06 & 0.810 \\
\hline Feed rate & 1 & 13.9193 & 4.4799 & 4.4799 & 6.20 & 0.028 \\
\hline Depth of cut & 1 & 0.2634 & 0.0932 & 0.0932 & 0.13 & 0.726 \\
\hline Cutting speed*Feed rate & 1 & 0.7534 & 2.2227 & 2.2227 & 3.08 & 0.105 \\
\hline Cutting speed*Depth of cut & 1 & 3.9861 & 0.0358 & 0.0358 & 0.05 & 0.828 \\
\hline Feed rate*Depth of cut & 1 & 0.0033 & 1.1002 & 1.1002 & 1.52 & 0.241 \\
\hline $\begin{array}{l}\text { Cutting speed*Feed rate* } \\
\text { Depth of cut }\end{array}$ & 1 & 1.5199 & 1.5199 & 1.5199 & 2.10 & 0.172 \\
\hline Error & 12 & 8.6649 & 8.6649 & 0.7221 & & \\
\hline Total & 19 & 31.9427 & & & & \\
\hline \hline
\end{tabular}

The experimental results were used to develop the mathematical models using RSM to determine the relationship between the electric current consumption and machining parameters without lubricant. Substituting the values in Eq. (2), the second order response surface representing the electric current consumption without lubricant (NL_CC) is given in the following equation.

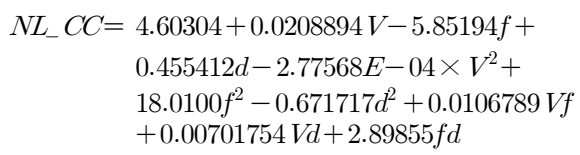

ANOVA was applied to study the effect of the input parameters on the electric current consumption without lubricant. Table 6 shows that there are no significant factors.

Based on the equations $3,4,5$, and 6 , we can predict the values of the response factors: surface roughness and electric current consumption with the results of experiments. The results of experiment and prediction on surface roughness and electric current consumption under both treatments were found to be almost the same as shown in Figures 4-7. 
Table 6 Results of analysis of variance for electric current consumption without lubricant

\begin{tabular}{l|c|c|c|c|c|c}
\hline \multicolumn{1}{c|}{ Source } & DF & Seq SS & Adj SS & Adj MS & F & P \\
\hline Cutting speed & 1 & 0.08649 & 0.00192 & 0.00192 & 0.08 & 0.785 \\
\hline Feed rate & 1 & 0.00484 & 0.00000 & 0.00000 & 0.00 & 0.994 \\
\hline Depth of cut & 1 & 0.06400 & 0.00002 & 0.00002 & 0.00 & 0.980 \\
\hline Cutting speed*Feed rate & 1 & 0.00245 & 0.00441 & 0.00441 & 0.18 & 0.680 \\
\hline Cutting speed*Depth of cut & 1 & 0.02880 & 0.00012 & 0.00012 & 0.00 & 0.946 \\
\hline $\begin{array}{l}\text { Feed rate*Depth of cut } \\
\text { Cutting speed*Feed rate* } \\
\text { Depth of cut }\end{array}$ & 1 & 0.02000 & 0.00000 & 0.00000 & 0.00 & 0.992 \\
\hline Error & 12 & 0.29602 & 0.29602 & 0.02467 & & \\
\hline Total & 19 & 0.51240 & & & & \\
\hline \hline
\end{tabular}

\section{Results and discussion}

Effect of machining parameters on the surface roughness and electric current consumption under various conditions, three levels of parameters and two different treatments for each level were analyzed using surface response method. The three-dimensional surface plots were generated considering two parameters at a time, while keeping the third parameter at the values of middle level in Table 1.

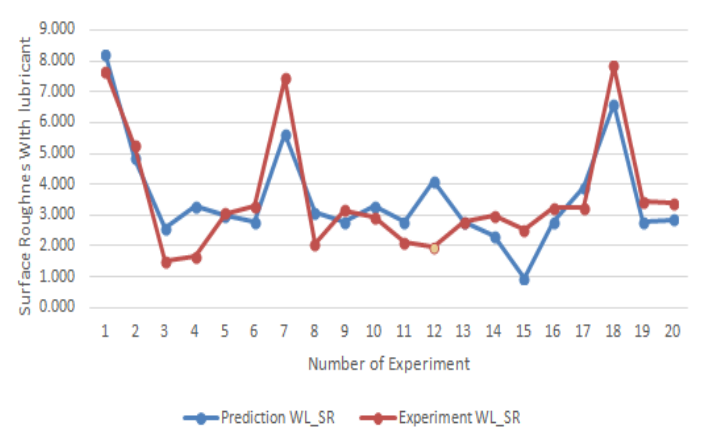

Fig. 4 Comparison of the results of experiment and prediction for surface roughness with lubricant

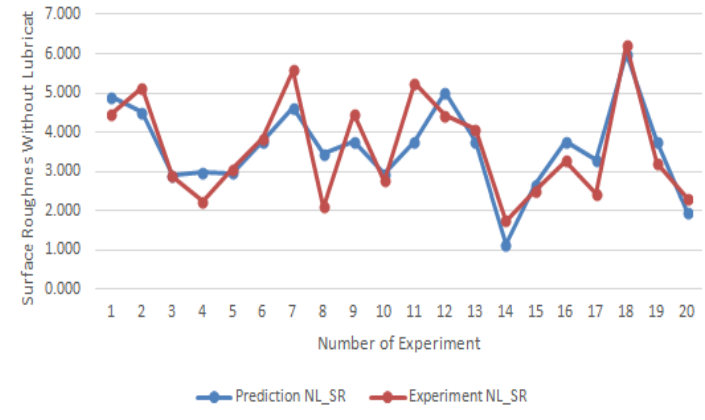

Fig. 5 Comparison of the results of experiment and prediction for surface roughness without lubricant

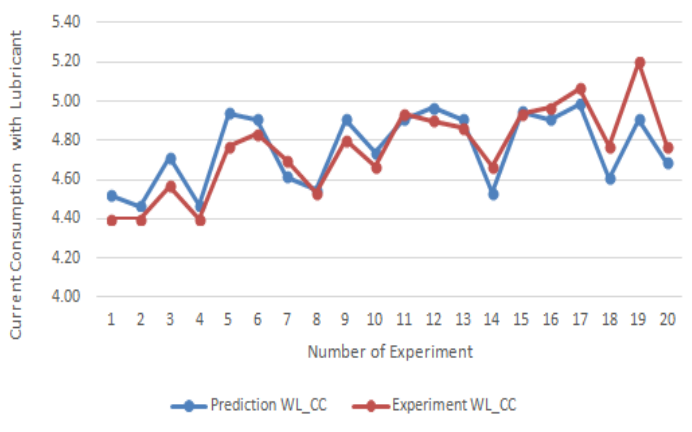

Fig. 6 Comparison of the results of experiment and prediction for electric current consumption with lubricant

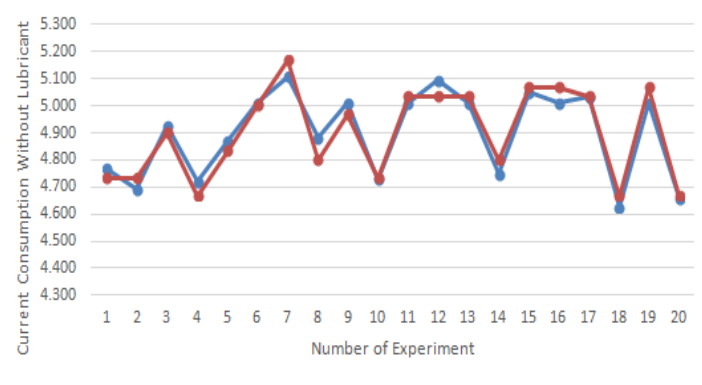

$\rightarrow$ Prediction NL_CC $\rightarrow$ Experiment NL_CC

Fig. 7 Comparison of the results of experiment and prediction for electric current consumption without lubricant 


\subsection{Effect of the machining parameters on} the surface roughness with lubricant

Figs. 8a-c shows the 3D surface graph for surface roughness by varying cutting parameters. It can be observed from Fig. 8a that the surface roughness was found to increase with increase in feed rate and depth of cut, keeping or holding the cutting speed at the middle level. Surface roughness will be highest when the levels of the feed rate and the depth of cut are high, but when the feed rate is at low level and the depth of cut is increased, the surface roughness will not increase. From Fig. 8b, surface roughness will sharply increase with the increase of feed rate, and the surface roughness will be highest when the level of cutting speed is low and the level of feed rate is high, keeping or holding the depth of cut at the middle level. Fig. $8 \mathrm{c}$ shows that the increase of cutting speed sharply decrease the surface roughness. The depth of cut will take effect for all level of cutting speed.

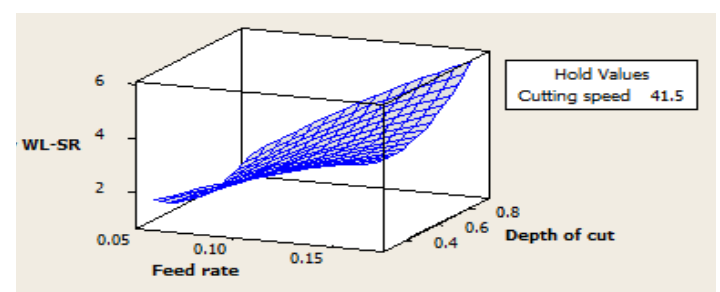

Fig. 8a 3D surface graph for surface roughness with lubricant as feed rate and depth of cut vary

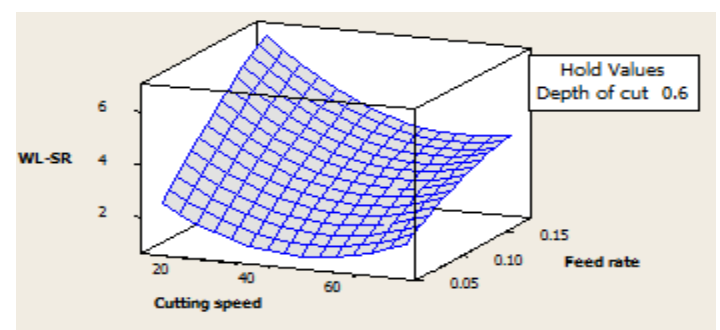

Fig. 8b 3D surface graph for surface roughness with lubricant as cutting speed and feed rate vary

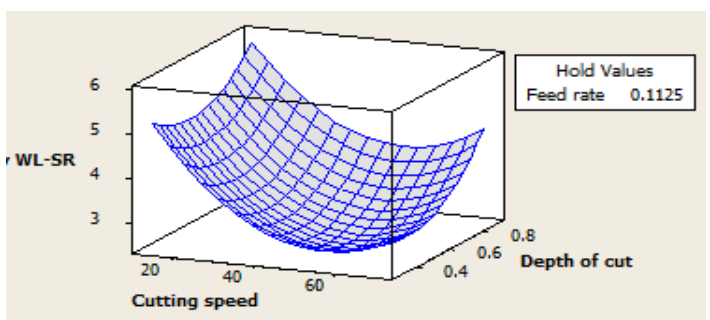

Fig. 8c 3D surface graph for surface roughness with lubricant as cutting speed and depth of cut vary

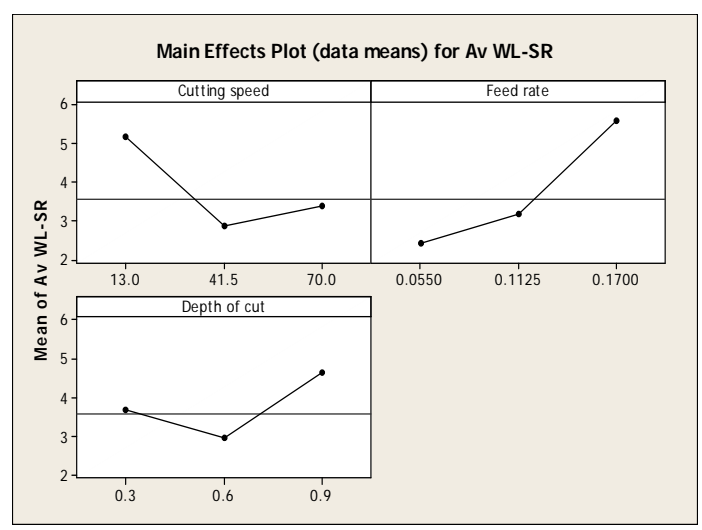

Fig. 9 Main effects plots for surface roughness with lubricant

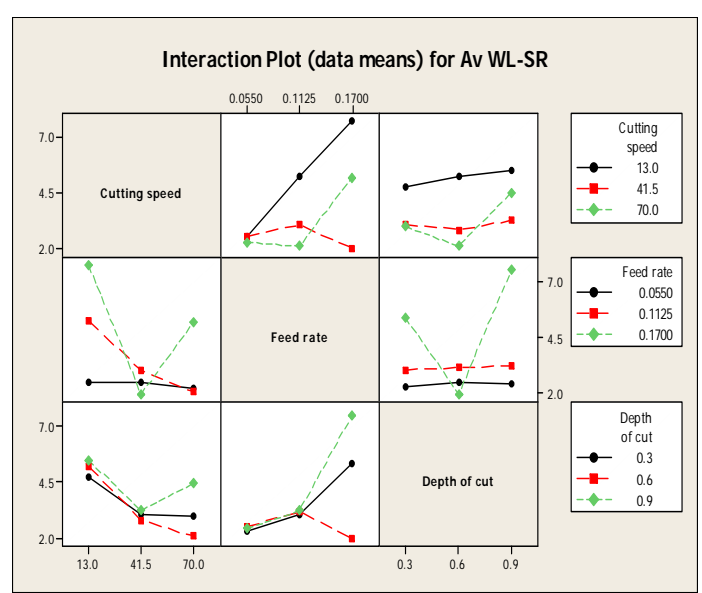

Fig. 10 Interaction plots of surface roughness

The main effects plot for surface roughness is shown in Fig. 9. The figure shows that feed rate has highest effect in reducing surface roughness. 
Fig. 10 shows the effects of other main factors and interactions.

\subsection{Effect of the machining parameters on the electric current consumption with lubricant}

Figs. 11a-c shows the 3D surface graph for electric current consumption by varying cutting parameters. Fig.11a shows that when the feed rate is low, the electric current consumption is low, but it will increase sharply when feed rate is at low level and level of depth of cut increases. From Fig. 11b,

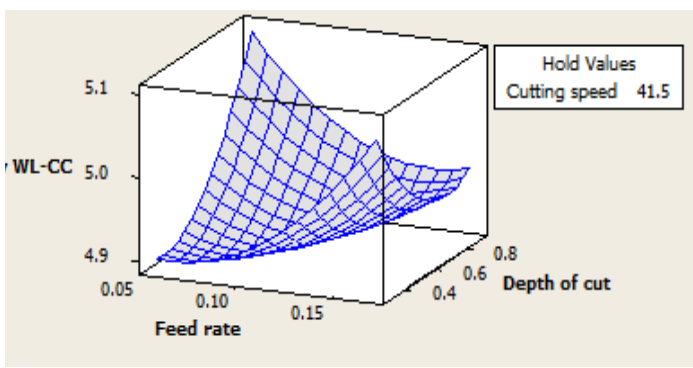

Fig. 11a 3D surface graph for electric current consumption with lubricant as feed rate and depth of cut vary

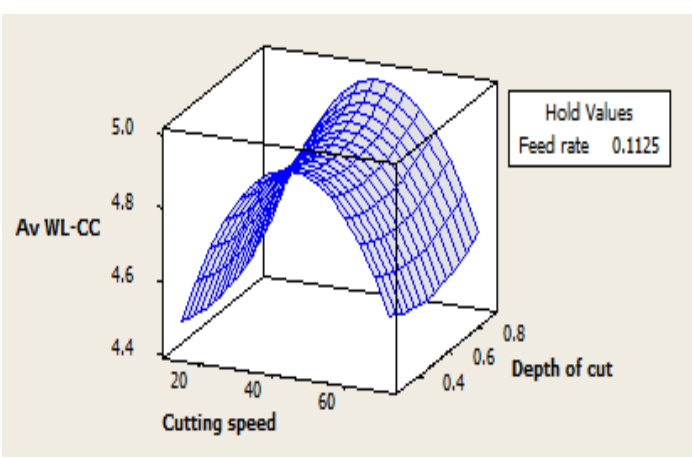

Fig. 11b 3D surface graph for electric current consumption with lubricant as cutting speed and depth of cut vary

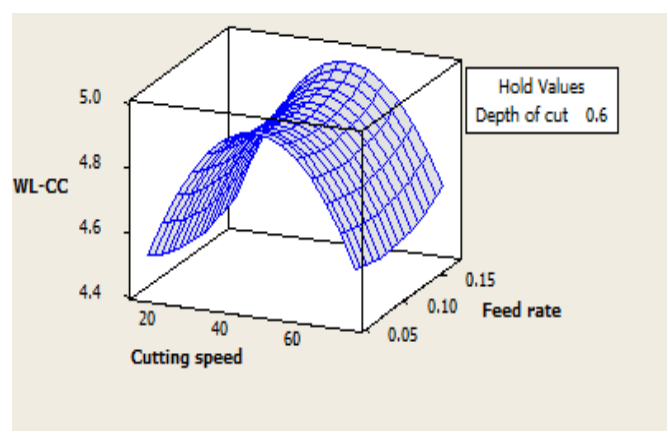

Fig. 11c 3D surface graph for electric current consumption with lubricant as cutting speed and feed rate vary

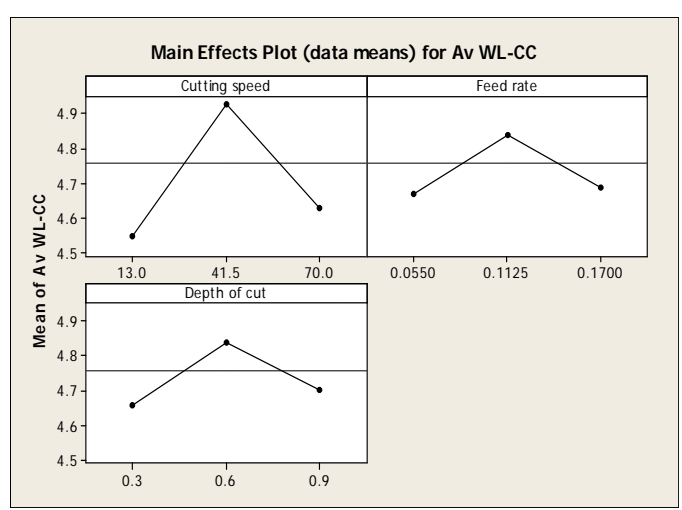

Fig. 12 Main effects plots for electric current consumption with lubricant

electric current consumption is low when cutting speed is low although the depth of cut is increased. When the cutting speed is increased up to the middle level, electric current consumption also is increased. At this level (medium level of cutting speed), if the depth of cut is increased, electric current consumption also is increased. Electric current consumption will be decreased when the level of cutting speed is at a high level. The same case will occur in the Fig. 11c, where depth of cut is replaced by feed rate.

Fig. 12 shows the main effects plot for electric current consumption. From the figure, it is seen that there is no significant influence on electric current 
consumption. This can be seen also in Table 4. Fig. 13 shows the interaction of all factors to electric current consumption. The interaction of each factor has little influence on the response variable.

\subsection{Effect of the machining parameters on the surface roughness without lubricant}

Figs.14a-c shows the 3D surface graph for surface roughness by varying cutting parameters. In Fig. $14 \mathrm{a}$, the surface roughness will sharply increase with the increase of feed rate while keeping or holding the cutting speed at the middle level. Surface roughness

will be highest when the level of feed rate is high. Depth of cut has little influence on this combination both when feed rate is at a low level and a high level. From Fig. 14b, surface roughness will sharply increases with the increase of feed rate and highest when the level of cutting speed is low and level of feed rate is high, keeping or holding the depth of cut at the middle level. Surface roughness will increase too when cutting speed is at a high level although not the same as cutting speed is at a low level, keeping depth of cut at middle level. Fig. 14c shows that the increase of cutting speed decreases the surface roughness. The depth of cut will affect to the surface roughness when cutting

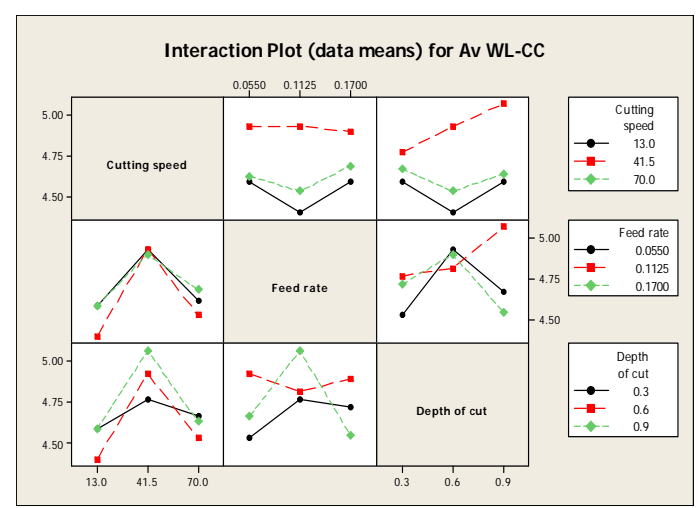

Fig. 13 Interaction plots of electric current consumption with lubricant

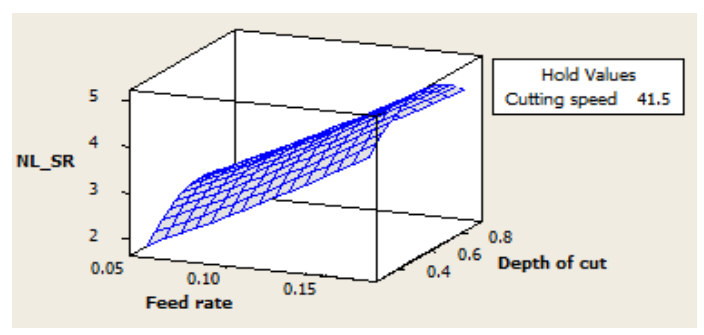

Fig. 14a 3D surface graph for surface roughness without lubricant as feed rate and depth of cut vary

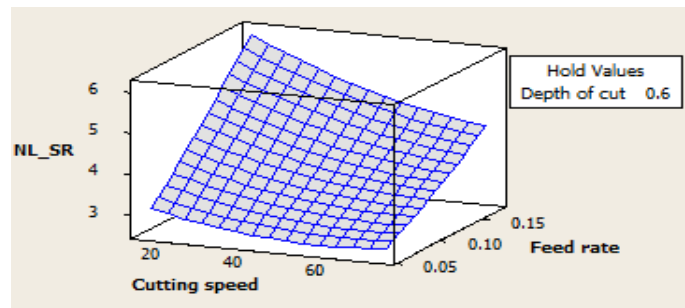

Fig. 14b 3D surface graph for surface roughness without lubricant as feed rate and depth of cut vary

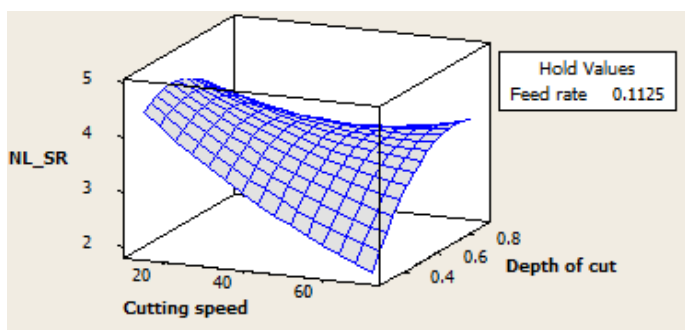

Fig. 14c 3D surface graph for surface roughness without lubricant as feed rate and depth of cut vary

speed is at a high level and the level of depth of cut is increased. In other words, the surface roughness will be low when cutting speed is at a high level but the depth of cut is at a low level.

The main effects plot for surface roughness is shown in Fig. 15. Feed rate is a factor that highly affects the surface roughness followed by cutting speed. Depth of cut have no influence on surface roughness. Fig. 16 shows that the interaction of 


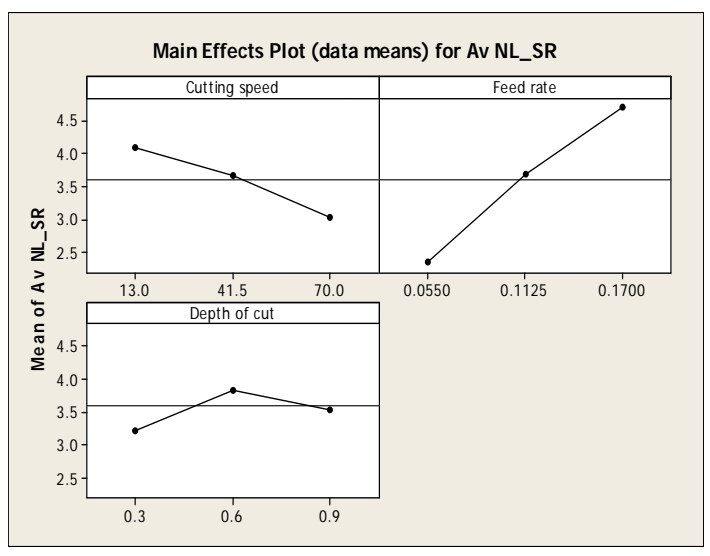

Fig. 15 Main effect plots for surface roughness without lubricant

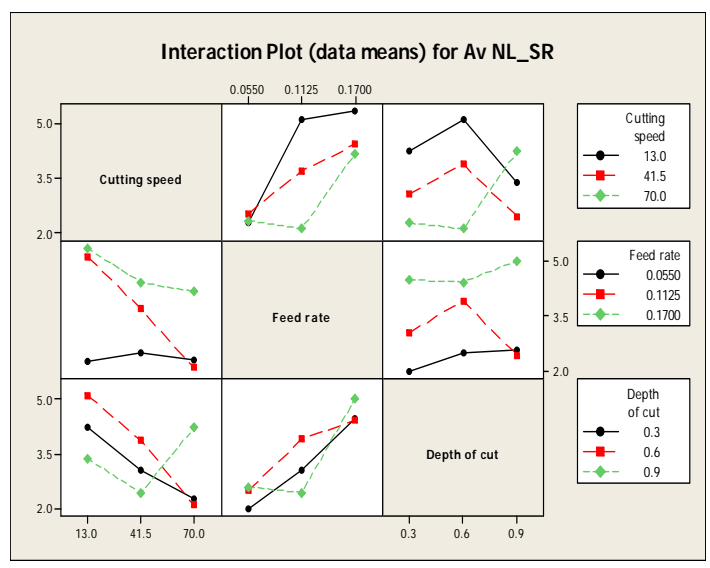

Fig. 16 Interaction plots of surface roughness without lubricant

each factors at different levels does not seem significant to the variable response.

\subsection{Effect of the machining parameters on the electric current consumption without lubricant.}

When the feed rate is high, the electric current consumption is sensitive to depth of cut, as depicted in Fig. 17a. The electric current consumption is increased sharply when the feed rate is at a high

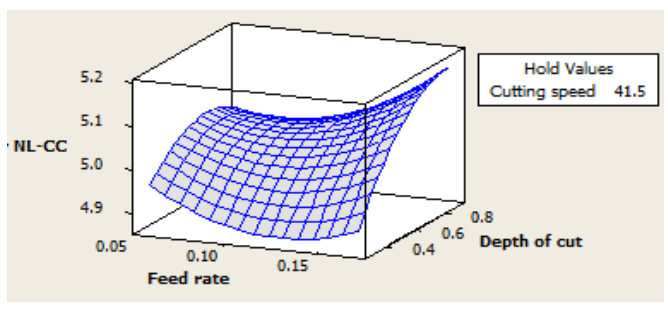

Fig. 17a 3D surface graph for electric cumrent consumption without lubricant as feed rate and depth of cut vary

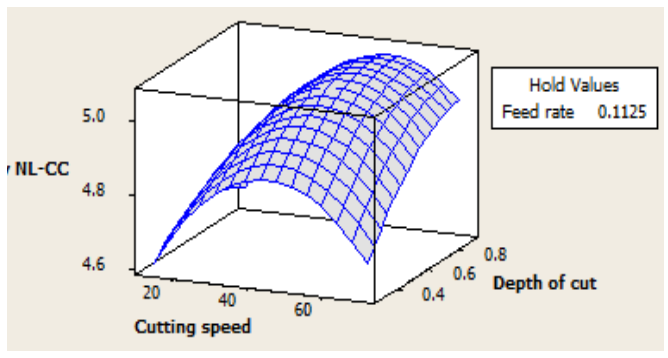

Fig. 17b 3D surface graph for electric current consumption without lubricant as cutting speed and depth of cut vary

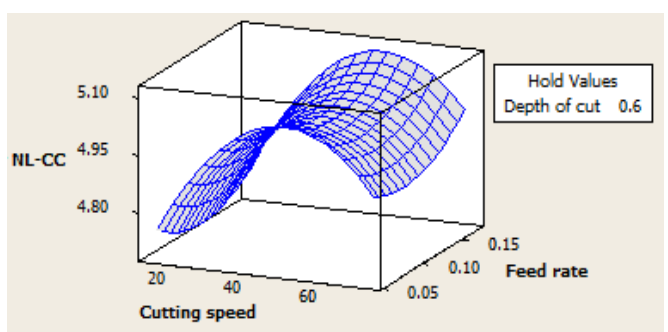

Fig. 17c 3D surface graph for electric current consumption without lubricant as cutting speed and feed rate vary

level and depth of cut is increased. Fig. 17b shows that the electric current consumption is low when cutting speed is at low level. When cutting speed is increased to the middle level, electric current consumption is also increased, at this level, when the depth of cut is increased the electric current consumption also is increased, however electric current consumption is reduced when cutting speed is at the high level. Fig. 17c shows that 


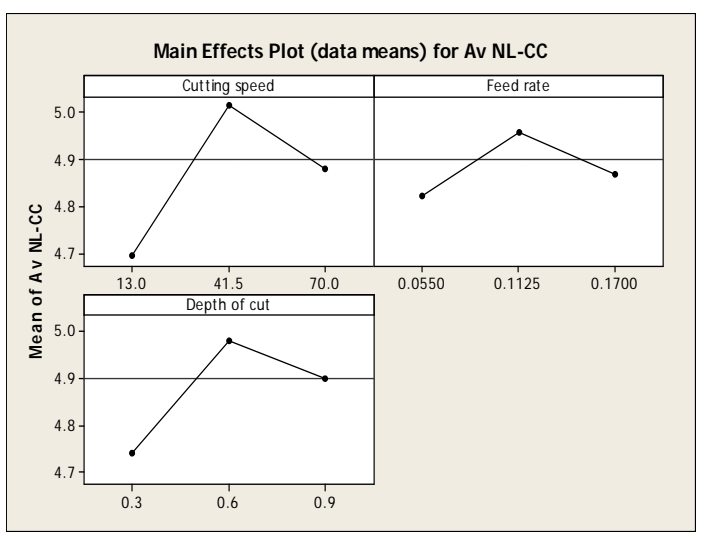

Fig. 18 Main effects plots for electric current consumption without lubricant

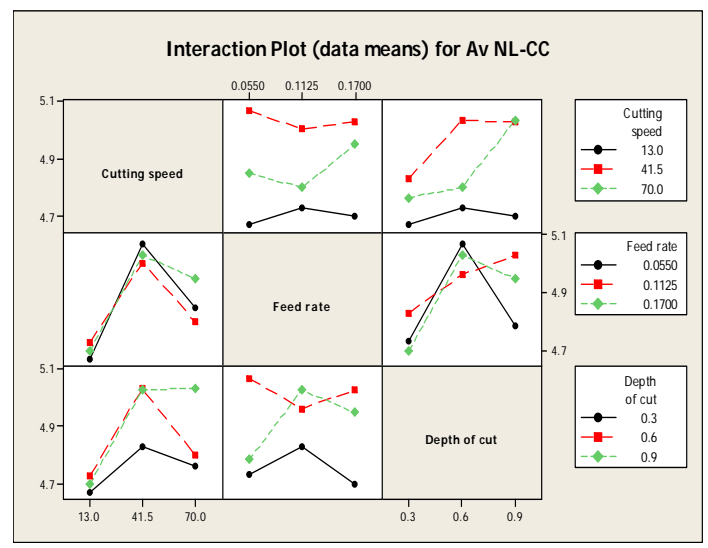

Fig. 19 Interaction plots of for electric cument consumption without lubricant

when cutting speed is at low level, the electric current consumption is also low, although the feed rate is increased. When the cutting speed is increased to the middle level, electric current consumption is also increased, at this level if the feed rate is increased, electric current consumption is also increased.

The main effect plot for electric current consumption without lubricant is shown on Fig. 18. From the figure it is seen that the factors have no significant influence on electric current consumption. This also can be seen in Table 6 (ANOVA). Fig. 18 shows the interaction of all factors to electric current consumption. The interaction of each factor has little influence on the response variable.

\subsection{Optimization}

The goals set and the limits for optimization for surface roughness and electric current consumption with lubricant are shown in Table 7. The goal used for both responses (surface roughness and electric current consumption with lubricant) is to minimize. The three factors such as cutting speed, feed rate and depth of cut must be between the minimum and maximum levels. Best solutions were obtained by using the desirability based approach in RSM. The best solution for both responses can be seen in Table 8 .

The goals set and the limits for optimization for surface roughness and electric current consumption without lubricant are shown in Table 9. The goal used for both responses is to minimize surface roughness and electric current consumption without lubricant. The three factor such as cutting speed, feed rate and depth of cut must be between the

Table 7 The goals set and the limits for optimization (with lubricant)

\begin{tabular}{c|c|c|c|c|c|c}
\hline Response & Goal & Lower & Target & Upper & Weight & Importance \\
\hline WL_SR & Minimum & 1.491 & 1.491 & 7.842 & 1 & 1 \\
\hline WL_CC & Minimum & 4.4 & 4.4 & 5.2 & 1 & 1 \\
\hline \hline
\end{tabular}

Table 8 Best global solutions for optimization (with lubricant)

\begin{tabular}{r|r|r|r|r}
\hline \hline \multicolumn{3}{c|}{ Factors } & \multicolumn{2}{c}{ Response } \\
\hline $\begin{array}{c}\text { Cutting } \\
\text { Speed } \\
(\mathrm{m} / \mathrm{min})\end{array}$ & $\begin{array}{c}\text { Feed Rate } \\
(\mathrm{mm} / \mathrm{Rev})\end{array}$ & $\begin{array}{c}\text { Depth of Cut } \\
(\mathrm{mm})\end{array}$ & $\begin{array}{c}\text { Soughness } \\
\text { Roum })\end{array}$ & $\begin{array}{c}\text { Electric } \\
\text { Current } \\
\text { Consumption } \\
\text { (A) }\end{array}$ \\
\hline 70 & 0.055 & 0.31 & 2.272 & 4.539 \\
\hline \hline
\end{tabular}


Table 9 The goals set and the limits for optimization (without lubricant)

\begin{tabular}{c|c|c|c|c|c|c}
\hline \hline Response & Goal & Lower & Target & Upper & Weight & Importance \\
\hline WL_SR & Minimum & 1.746 & 1.746 & 6.237 & 1 & 1 \\
\hline WL_CC & Minimum & 4.67 & 4.67 & 5.03 & 1 & 1 \\
\hline \hline
\end{tabular}

Table 10 Best global solutions for optimization (without lubricant)

\begin{tabular}{c|c|c|c|c}
\hline \hline \multicolumn{3}{c|}{ Factors } & \multicolumn{2}{c}{ Response } \\
\hline $\begin{array}{c}\text { Cutting } \\
\text { Speed } \\
(\mathrm{m} / \mathrm{min})\end{array}$ & $\begin{array}{c}\text { Feed Rate } \\
(\mathrm{mm} / \mathrm{Rev})\end{array}$ & $\begin{array}{c}\text { Depth of Cut } \\
(\mathrm{mm})\end{array}$ & $\begin{array}{c}\text { Surface } \\
\text { Roughness } \\
(\mathrm{um})\end{array}$ & $\begin{array}{c}\text { Electric } \\
\text { Current } \\
\text { Consumption } \\
\text { (A) }\end{array}$ \\
\hline 13 & 0.055 & 0.9 & 1.957 & 4.659 \\
\hline
\end{tabular}

minimum and maximum levels. The best solutions obtained for both responses can be seen in Table 10.

\section{Conclusion}

In this study, response surface methodology to model, analyze, predict and optimize the machining parameters is proposed. The machining parameters include cutting speed, feed rate and depth of cut. Two different treatments for each level (with and without lubricant) are also proposed to determine the effect of the parameters on surface roughness and electric current consumption on turning process of low carbon steel.

The feed rate has a significant effect on surface roughness followed by cutting speed and depth of cut with and without lubricant, so it is important to control and determine the level of feed rate. The electric current consumption highly depends on the level of cutting speed and depth of cut, whereas feed rate does not affect to the electric current consumption. Response surface optimization shows that the optimal combination of machining parameters are $70 \mathrm{~m} / \mathrm{min}$ of cutting speed, 0.055 $\mathrm{mm} / \mathrm{rev}$ of feed rate and $0.310 \mathrm{~mm}$ of depth of cut under with lubricant and $13 \mathrm{~m} / \mathrm{min}$ of cutting speed, $0.055 \mathrm{~mm} / \mathrm{rev}$ of feed rate and $0.9 \mathrm{~mm}$ of depth of cut under without lubricant.

\section{References}

(1) Ahilan at al., "Modeling and prediction of machining quality in $\mathrm{CNC}$ turning process using intelligent hybrid decision making tools", Applied Soft Computing, Vol. 13, pp. 1543-1551, 2013.

(2) Benardos, P.G.,Vosniakos G.C, "Predicting surface roughness in machining: a review", International Journal of Machine Tools \& Manufacture, Vol. 43, pp. 833-844, 2003.

(3) Bhattacharya at al., "Estimating the effect of cutting parameters on surface finish and power consumption during high speed machining of AISI 1045 steel using Taguchi design and ANOVA", Prod. Eng. Res. Devel, Vol. 3, pp. 31-40, 2009.

(4) Davim at al. "Investigations into the effect of cutting conditions on surface roughness in turning of free machining steel by ANN models", Journal of materials processing technology, Vol. 205, pp. 16-23, 2008.

(5) Ezilarasan at al., "An experimental analysis and measurement of process performances in machining of nimonic C-263 super alloy", Measurement, Vol. 46, pp. 185-199, 2013.

(6) Hamdan at al., "An optimization method of the machining parameters in high-speed machining of stainless steel using coated carbide tool for best surface finish", Int. J. Adv Manuf. Technol, Vol. 58, pp. 81-91, 2012.

(7) Jafarian at al., "Improving surface integrity in finish machining of Inconel 718 alloy using intelligent systems", Int. J. Adv Manuf. Technol, Vol. 71, pp. 817-827, 2014. 
(8) Joardar at al., "Application of response surface methodology for determining cutting force model in turning of LM6/SiCP metal matrix composite", Measurement, Vol. 47, pp. 452-464, 2014.

(9) Kaynak., "Evaluation of machining performance in cryogenic machining of Inconel 718 and comparison with dry and MQL machining", Int. J. Adv Manuf. Technol, Vol. 72, pp. 919-933, 2014.

(10) Makadia and Nanavati, "Optimization of machining parameters for turning operations based on response surface methodology", Measurement, Vol. 46, pp. 1521-1529, 2013.

(11) Montgomery, C., "Design and Analysis of experiments", 4th ed. Wiley, New York, 1997.

(12) Neseli at al., "Optimization of tool geometry parameters for turning operations based on the response surface methodology", Measurement, Vol. 44, pp. 580-587, 2011.

(13) Sarikaya and Gullu, "Taguchi design and response surface methodology based analysis of machining parameters in CNC turning under MQL", Journal of Cleaner Production, Vol. 65, pp. 604-616, 2014.

(14) Suresh at al., "Predictive modeling of cutting forces and tool wear in hard turning using response surface methodology", Procedia Engineering, Vol. 38, pp. 73-81, 2012.

(15) Singh and Rao, "A surface roughness prediction model for hard turning process", Int. J. Adv Manuf. Technol, Vol. 32, pp. 1115-1124, 2007. (16) Palanikumar, "Application of Taguchi and response surface methodologies for surface roughness in machining glass fiber reinforced plastics by PCD tooling”, Int. J. Adv Manuf. Technol, Vol. 36, pp. 19-27, 2008. 